Check for updates

Cite this: RSC Adv., 2018, 8, 31414

Received 18th July 2018

Accepted 27th August 2018

DOI: 10.1039/c8ra06102e

rsc.li/rsc-advances

\section{Flexible and high energy density solid-state asymmetric supercapacitor based on polythiophene nanocomposites and charcoal $\dagger$}

\author{
Vijeth H., (D) Ashokkumar S. P., Yesappa L., Niranjana M., Vandana M. \\ and Devendrappa H. (D)*
}

\begin{abstract}
An asymmetric supercapacitor (ASC) was constructed using a polythiophene/aluminium oxide (PTHA) nanocomposite as an anode electrode and charcoal as a cathode electrode. The highest specific capacitance $\left(C_{\mathrm{sp}}\right)$ of the PTHA electrode was found to be $554.03 \mathrm{~F} \mathrm{~g}^{-1}$ at a current density (CD) of $1 \mathrm{~A} \mathrm{~g}^{-1}$ and that of the charcoal electrode was $374.71 \mathrm{~F} \mathrm{~g}^{-1}$ at $1.4 \mathrm{~A} \mathrm{~g}^{-1}$, measured using a three electrode system. The maximum $C_{\mathrm{sp}}$ obtained for the assembled PTHA//charcoal asymmetric supercapacitor (ASC) was $265.14 \mathrm{~F} \mathrm{~g}^{-1}$ at $2 \mathrm{~A} \mathrm{~g}^{-1}$. It also showed a high energy density of $42.0 \mathrm{~W} \mathrm{~h} \mathrm{~kg}^{-1}$ at a power density of $735.86 \mathrm{~W} \mathrm{~kg}^{-1}$ and capacitance retention of $94.61 \%$ even after 2000 cycles. Moreover, it is worth mentioning that the asymmetric device was used to illuminate a light emitting diode (LED) for more than 15 minutes. This PTHA//charcoal ASC also possesses stable electrochemical properties in different bending positions and hence finds a promising application in flexible, wearable and portable energy storage electronic devices.
\end{abstract}

\section{Introduction}

Electrochemical capacitors or supercapacitors (SCs) are one of the widely used promising electrochemical energy storage devices which provide superior energy density, power density, rapid charging-discharging rate and long cycle life and can fill the gap amongst batteries and normal capacitors. ${ }^{1}$ Recently, the flexible supercapacitors have become favorable contenders for portable and wearable energy storage electronic devices.. ${ }^{2-6}$ Mainly, supercapacitors can be categorized into electrical double layer capacitors (EDLCs) and pseudocapacitors (PC) based on the various charge storage mechanisms. ${ }^{7,8}$ In general, the energy storage process shows electrostatic behavior in EDLCs and separation of charges takes place at the interface of the electrode and electrolyte. Conventional carbon based materials like activated carbon, carbon nanotubes, graphene $e^{9-11}$ etc. are commonly used in EDLCs, whereas in pseudocapacitors the charge storage mechanism is faradic in nature i.e., electron charge transfer takes place between the electrode and electrolyte. ${ }^{7}$ Conducting polymers are suitable as pseudocapacitor electrode materials because of their significant advantages in intrinsic flexibility and high electrical conductivity compared to other materials which makes them perfect candidates for highperformance flexible SCs. For this purpose, conducting

Department of Physics, Mangalore University, Mangalagangothri, 574199, India. E-mail: dehu2010@gmail.com

$\dagger$ Electronic supplementary information (ESI) available. See DOI: 10.1039/c8ra06102e polymers like polyaniline, polypyrrole, polythiophene ${ }^{12-15}$ and metal oxides like $\mathrm{RuO}_{2}, \mathrm{MnO}_{2}, \mathrm{NiO}, \mathrm{Co}_{3} \mathrm{O}_{4}, \mathrm{ZnO}$ and $\mathrm{Al}_{2} \mathrm{O}_{3}$ (ref. 15-20) composites are used to develop desirable and flexible energy storage devices. Among the mentioned conducting polymers, polythiophene (PTH) is specifically suitable and appropriate for SC fabrication ${ }^{21}$ because of its excessive pseudocapacitance, high electrical conductivity, high energy density, low cost, and environmentally friendly nature..$^{22,23}$ However, the metal oxides have received more interest due to their enhancement in the electrochemical parameters like high $C_{\mathrm{sp}}$, cycle life, energy density and also high electrical conductivity. Many attempts were done to fabricate pseudocapacitor using conducting polymer with metal oxide composite. Among various metal oxides, $\mathrm{MnO}_{2}$ has been extensively studied as they exhibits high pseudocapacitance and theoretical specific capacitance, energy density and longer cycle life. ${ }^{24}$ Jalal Arjomandi et. al., reported high performing supercapacitor electrode material based on polyaniline/aluminium oxide ${ }^{20}$ with the specific capacitance of $292 \mathrm{~F} \mathrm{~g}^{-1}$ and $91 \%$ capacitance retention over 8000 cycles. These results show that high $C_{\mathrm{sp}}$ and extensive cyclic stability can be achieved if the conducting polymer is composited with $\mathrm{Al}_{2} \mathrm{O}_{3}{ }^{25}$

Advanced SCs have been fabricated for practical application with high operating potential and energy density without compromising power density and cyclic stability. As energy density of SCs is $E=\frac{1}{2} C_{\mathrm{sp}} V^{2}$, by improving the $C_{\mathrm{sp}}$ and operating potential $(V)$ one can enhance the energy density. In order to increase both $C_{\mathrm{sp}}$ and $V$ the promising way is to develop the 
asymmetric SC device. In this concern, ASC was constructed using battery sort of faradic cathode (energy source) and capacitor like anode (power source) which offers many advantages like high $C_{\mathrm{sp}}$ and long cycle life from supercapacitor and energy density from battery type electrode. ${ }^{26-28}$ Moreover, electrochemical properties of ASC depend on the potential window of two electrodes. Many researchers have studied the performance of asymmetric SCs based on materials like activated carbon GO/PPy/AC, G/ $\mathrm{MnO}_{2} / / \mathrm{AC}$ and PANI/AC. ${ }^{29-31}$

In this work, it is focussed on enhancing the power density, energy density, and life cycle of supercapacitors. The main objective of the work is to identify the highly efficient device with low cost, large scale production, environmental friendly anode and cathode electrodes. Charcoal has been chosen as one of the prominent cathode electrode material since it has large surface area and high electrical conductivity which will enhance the transport of electrolyte ions and leads to high energy storage capacity. ${ }^{32,33}$ Polymer nanocomposites with size less than $100 \mathrm{~nm}$ possess high surface-to-volume ratio which allows fast transport of electrolyte ions ${ }^{\mathbf{2 0}}$ in SCs while the activated carbon with large surface area will enhance the absorption/desorption of electroactive species, thus leading to high performance asymmetric supercapacitor.

For the first time, we have fabricated a flexible solid state ASC using polythiophene $/ \mathrm{Al}_{2} \mathrm{O}_{3}$ nanocomposite as an anode electrode and a charcoal-based cathode electrode. The camphor sulfonic acid surfactant assisted polythiophene $/ \mathrm{Al}_{2} \mathrm{O}_{3}$ nanocomposite was synthesized by chemical polymerization method with various mass ratios of $\mathrm{Al}_{2} \mathrm{O}_{3}$, and PTHA//charcoal ASC device was fabricated. This work gives a new approach to the broader application of highly flexible ASC in portable and wearable energy storage devices.

\section{Experimental techniques}

\subsection{Materials}

The monomer thiophene $\left(\mathrm{C}_{4} \mathrm{H}_{4} \mathrm{~S}\right)$ (Sigma-Aldrich, 99\%), camphor sulfonic acid (CSA) (Sigma-Aldrich, 99\%), and polyvinylidene difluoride (PVDF) (Sigma-Aldrich, 99\%) were used without further purification. Aluminium oxide $\left(\mathrm{Al}_{2} \mathrm{O}_{3}\right)$ powder, polyvinyl alcohol (PVA), potassium hydroxide (KOH), APS $\left(\mathrm{NH}_{4}\right)_{2} \mathrm{~S}_{2} \mathrm{O}_{8}$ (mol. wt $228.20 \mathrm{~g}$ ), $\mathrm{N}$-methyl pyrrolidine (NMP), charcoal (activated carbon) from Merck chemicals and deionized (DI) water was used throughout the experiments.

\subsection{Synthesis of polythiophene $/ \mathrm{Al}_{2} \mathrm{O}_{3}$ nanocomposites}

$0.01 \mathrm{M}$ camphor sulfonic acid (CSA) and $0.1 \mathrm{M}$ thiophene monomer was dispersed in $30 \mathrm{ml}$ of DI water and these solutions were stirred thoroughly for about 60 minutes; $0.1 \mathrm{M}$ solution of ammonium peroxydisulphate (APS) is prepared in $60 \mathrm{ml}$ of DI water and this solution was added dropwise to the monomer solution with constant stirring. This mixture solution was heated at $85{ }^{\circ} \mathrm{C}$ for 24 hours without stirring to get a black precipitate. The precipitate was rinsed with methanol and double distilled water for few times to remove the impurities and unreacted contents. Finally, the obtained product was dried in an oven for 5 hours at $80{ }^{\circ} \mathrm{C}$ to get a brownish black colored PTH powder.

The polythiophene $/ \mathrm{Al}_{2} \mathrm{O}_{3}$ nanocomposites were synthesized using the same above procedure by adding $1 \mathrm{wt} \%, 2 \mathrm{wt} \%$ and $5 \mathrm{wt} \%$ of $\mathrm{Al}_{2} \mathrm{O}_{3}$ into the primary monomer solution and coded as PTHA1, PTHA2, and PTHA5 respectively.

\subsection{Fabrication of asymmetric supercapacitor}

The fabrication of PTHA electrode was done by mixing the PTHA sample, carbon black and PVDF with a mass ratio of $80: 10: 10$ in NMP solution. The obtained slurry was pasted uniformly on to the copper foil $(1 \times 1 \mathrm{~cm})$ and dried at $80{ }^{\circ} \mathrm{C}$ for 6 hours. This PTHA electrode was used as an anode electrode in the ASC device. The cathode electrode was fabricated using a paste of charcoal and PVDF prepared with a mass ratio of $90: 10$ in NMP solution and pasted on to the copper foil $(1 \times 1$ $\mathrm{cm})$. The $\mathrm{PVA} / \mathrm{KOH}$ gel electrolyte was prepared as in the previously reported study. ${ }^{34}$ In this process, 3 gram of PVA was dissolved in $30 \mathrm{ml}$ of DI water under rigorous stirring and 3 gram of $\mathrm{KOH}$ was dissolved in another $30 \mathrm{ml}$ of DI water. The prepared solutions were mixed together and heated for 1 hour at $80{ }^{\circ} \mathrm{C}$ under rigorous stirring till a gel electrolyte was formed. A solid-state ASC device was assembled by sandwiching a thin layer of PVA/KOH gel electrolyte between PTHA and charcoal electrode and is separated by a Whatmann paper.

\subsection{Nanocomposite characterisation and electrochemical measurements}

The chemical compositions of the synthesized PTHA nanocomposites were studied using X-ray photoelectron spectroscopy (XPS) technique (AXIS ULTRA from AXIS 165). Surface morphology of PTH and PTHA nanocomposites were examined using atomic force microscopy (AFM Bruker) in the tapping mode. The sample for AFM characterization was made by drop casting the PTH and PTHA nanocomposites on a silicon wafer. Thermal behavior was examined by thermogravimetric analysis using TGA instrument in a temperature range of $0-900{ }^{\circ} \mathrm{C}$ with a heating rate of $5{ }^{\circ} \mathrm{C} \min ^{-1}$.

The electrochemical characterization such as CV test, GCD study and impedance spectroscopy studies were made using three electrodes configuration, with a platinum rod as a counter electrode, $\mathrm{Ag} / \mathrm{AgCl}$ as a reference electrode and fabricated composite electrode as a working electrode in $1 \mathrm{M} \mathrm{KCl}$ aqueous electrolyte solution. All the electrochemical performances were studied using electrochemical workstation model CHI 660E.

\section{Results and discussion}

\subsection{XPS analysis}

In-depth information about the surface chemical composition of the synthesized PTH and PTHA nanocomposites was acquired by XPS spectra. The resolved spectra of C1s, O1s, S2p and $\mathrm{Al} 2 \mathrm{p}$ and wide scan (survey spectrum) are shown in Fig. 1(a). The survey scan spectrum confirms the presence of chemicals such as carbon (C), oxygen (O), sulphur (S) and aluminium (Al) in PTHA nanocomposite. 


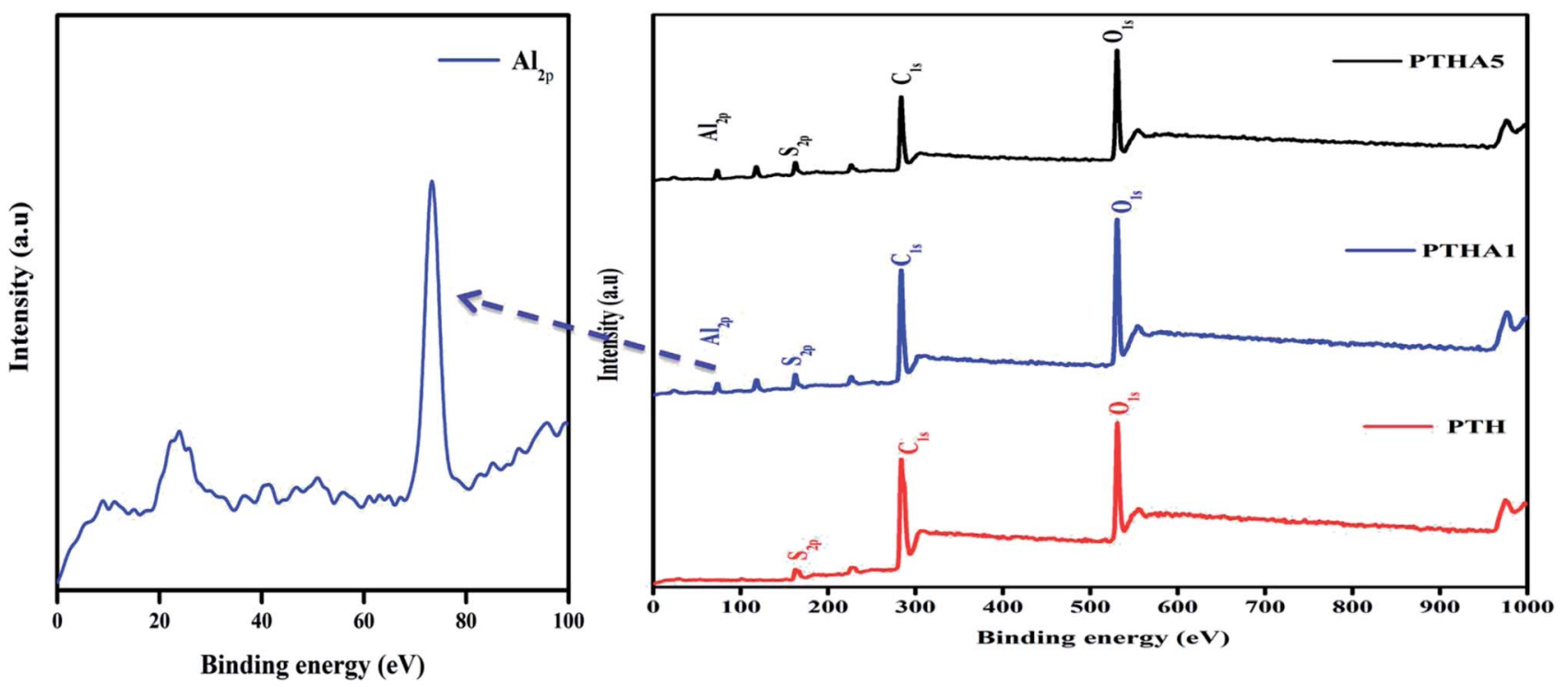

Fig. 1 XPS survey scan spectra of pure PTH, PTHA1, and PTHA5 and enlarged portion of Al2p peak.

The deconvoluted high-resolution spectrum further confirms the structure, and well-defined core level spectra of the compound. Fig. 2(a) shows the C1s core level spectra decomposed into three peaks. The lowest binding energy peak at $284.69 \mathrm{eV}$ is ascribed to $\alpha$ and $\beta$ aromatic carbons of PTH backbone. The peak at $285.64 \mathrm{eV}$ is linked with $\mathrm{C}-\mathrm{S}$ bond and that at $288.47 \mathrm{eV}$ resembles the $\mathrm{C}-\mathrm{O}$ bond respectively. Fig. 2(b) represents core-level $\mathrm{O} 1 \mathrm{~s}$ spectrum of PTHA nanocomposite; the peak observed at lower binding energy $(531.39 \mathrm{eV})$ is attributed to $\mathrm{Al}-\mathrm{O}-\mathrm{Al}$ bond and the peak at $532.92 \mathrm{eV}$ is assigned to $\mathrm{OH}$ groups.

In Fig. 2(c), the $S 2 p$ peak can be deconvoluted into three peaks as $\mathrm{S} 2 \mathrm{p}_{3 / 2}$ at $162.65 \mathrm{eV}$ and $\mathrm{S} 2 \mathrm{p}_{1 / 2}$ at $163.69 \mathrm{eV}$ which corresponds to sulphur in thiophene, ${ }^{35}$ while the peak positioned at about $167.79 \mathrm{eV}$ is attributed to $\mathrm{SO}_{3}{ }^{2-}$ group. ${ }^{36}$ The $\mathrm{S} 2 \mathrm{p}$ spectra suggests the successful polymerization of thiophene. The Al2p XPS spectrum of the nanocomposite is shown in Fig. 2(d). The two peaks at $74.34 \mathrm{eV}$ and $75.46 \mathrm{eV}$ are assigned to the $\mathrm{Al} 2 \mathrm{p}_{3 / 2}$ and $\mathrm{Al} 2 \mathrm{p}_{1 / 2}$ from $\mathrm{Al}_{2} \mathrm{O}_{3} \cdot{ }^{37}$ The above analysis suggests the successful synthesis of PTHA nanocomposites.

\subsection{Atomic force microscopy}

AFM is a powerful tool to study the structural morphology and surface roughness of the compounds. AFM images of PTH and PTHA nanocomposites on a silicon wafer are shown in Fig. 3. The images show the spherical morphology with particle size ranging from 60 to $150 \mathrm{~nm}$ in diameter. A uniform arrangement of particles is seen in PTH, whereas a small amount of aggregation can be seen in PTHA samples.

The AFM 3-D micrograph images of PTH and PTHA2 show uniform and homogeneous morphology with high prominent flakes having an average height of $\sim 150 \mathrm{~nm}$. This result indicates the compatibility of the polymer matrix with nanoparticles. It is further verified by considering the surface roughness of the PTH and PTHA nanocomposites. The average surface roughness obtained from the topographical analysis ( 1 $\mu \mathrm{m}$ to $2 \mu \mathrm{m}$ areas) is 25.4 and $30.8 \mathrm{~nm}$ which indicates that the PTH exhibit smooth surface than the PTHA nanocomposites. The smoothness of the PTH surface indicates the amorphous nature. These morphological differences seen in the nanocomposites can affect their physical properties. ${ }^{38}$

\subsection{TGA analysis}

The thermogravimetric analysis (TGA) gives the information about thermal properties of the composites as shown in Fig. 4(a).

The TGA curve of PTH shows decomposition in two steps. The first decomposition is about $4.26 \%$ which is due to moisture and water on the surface of the materials and the thermogram is stable up to $190{ }^{\circ} \mathrm{C}$. From $190{ }^{\circ} \mathrm{C}$ the thermogram shows a fast decomposition with a weight loss of $89.91 \%$ which ends at $626^{\circ} \mathrm{C}$ as shown in Fig. 4(b).

The second major weight loss is because of the removal of elements such as carbon, hydrogen, and sulphur in thiophene monomer. ${ }^{39}$ The PTHA nanocomposite also shows two stages of weight loss which are summarised in Table S1. $\dagger$ In comparison with PTH, the weight loss of PTHA nanocomposites is found to be relatively decreased. A total weight loss of 59.55\%, 36.00\%, and $29.84 \%$ is found in PTHA1, PTHA2, and PTHA5 respectively. Incorporation of the nanocomposite into polythiophene (in the presence of surfactant) is expected to enhance the thermal stability of polythiophene. It is noted that PTH shows $20.86 \%$ retention up to $550{ }^{\circ} \mathrm{C}$, whereas PTHA1, PTHA2, and PTHA5 show $52.02 \%, 36.12 \%$ and $31.76 \%$ retention up to $550{ }^{\circ} \mathrm{C}$ respectively. Fig. 4(b) shows that PTHA nanocomposites are more stable than the PTH.

\subsection{Current-voltage characteristics}

Fig. 5 shows the temperature-dependent $I-V$ characteristics of PTH and PTHA5 nanocomposite. The $I-V$ characteristics show 

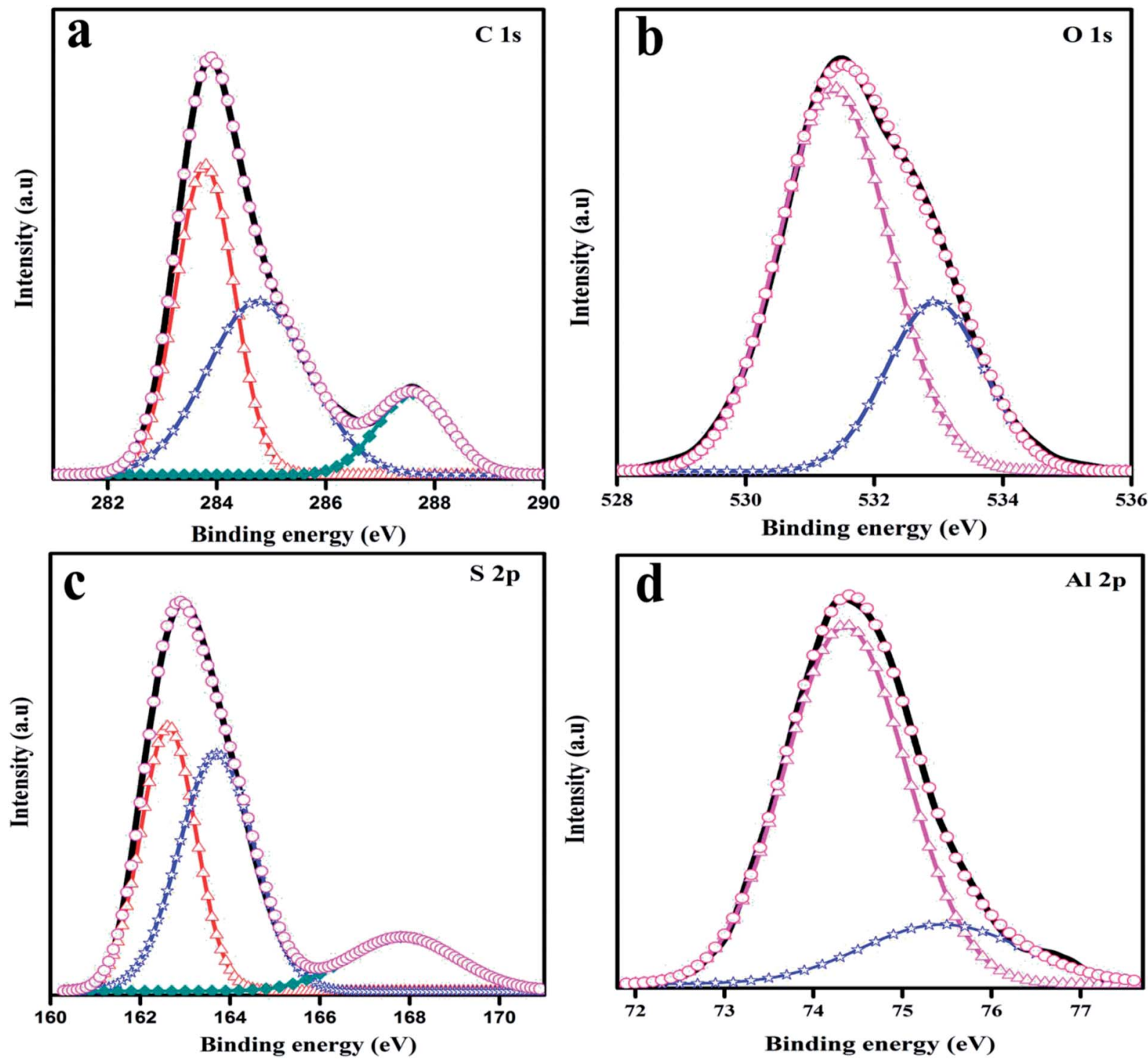

Fig. 2 Deconvoluted spectra for (a) C1s (b) O1s (c) S2p and (d) Al2p.

almost linear relationship and it is to be noticed that the value of current increases with the applied voltage and increase in the temperature.

The value of dc conductivity $(\sigma)$ can be calculated using the $I-V$ curve of PTH and PTHA5 nanocomposite using below equation.

$$
\sigma_{\mathrm{dc}}=\frac{I l}{V A}
$$

where $I$ (A) represent the current, $l$ is the thickness of the sample, $V$ is the voltage and $A$ is cross-sectional area of the sample. The dc conductivity is found to be $1.8 \times 10^{-5} \mathrm{~S} \mathrm{~cm}^{-1}$ and $1.9 \times 10^{-3} \mathrm{~S} \mathrm{~cm}^{-1}$ for PTH and PTHA5 nanocomposite respectively. These obtained results indicate that there is an enhancement in the dc conductivity of PTHA5 nanocomposite compared to pure PTH.

\subsection{Electrochemical characterisation}

To study the electrochemical performance of PTHA5 and charcoal electrode using cyclic voltammetry (CV) test, galvanostatic charging/discharging (GCD), impedance spectroscopy studies were carried out. The $\mathrm{CV}$ measurements at different scan rate were done using 3-electrode configuration in $1 \mathrm{M} \mathrm{KCl}$ aqueous electrolyte. Fig. 6(a) shows the CV curves of PTHA5 electrode, a pair of redox peaks appeared which represents pseudocapacitance behavior with good charge diffusion at the electrode surface. The cyclic voltammetry curves for various scan rates from 10 to $100 \mathrm{mV} \mathrm{s}^{-1}$ were collected. It was clearly noticed that at higher scan rates, cathodic peak shifts towards positive side and anodic peak shifts towards the negative side due to the internal resistance occurred in the electrode. Also, area of CV curve increases with the increase in the scan rate showing good rate performance. 

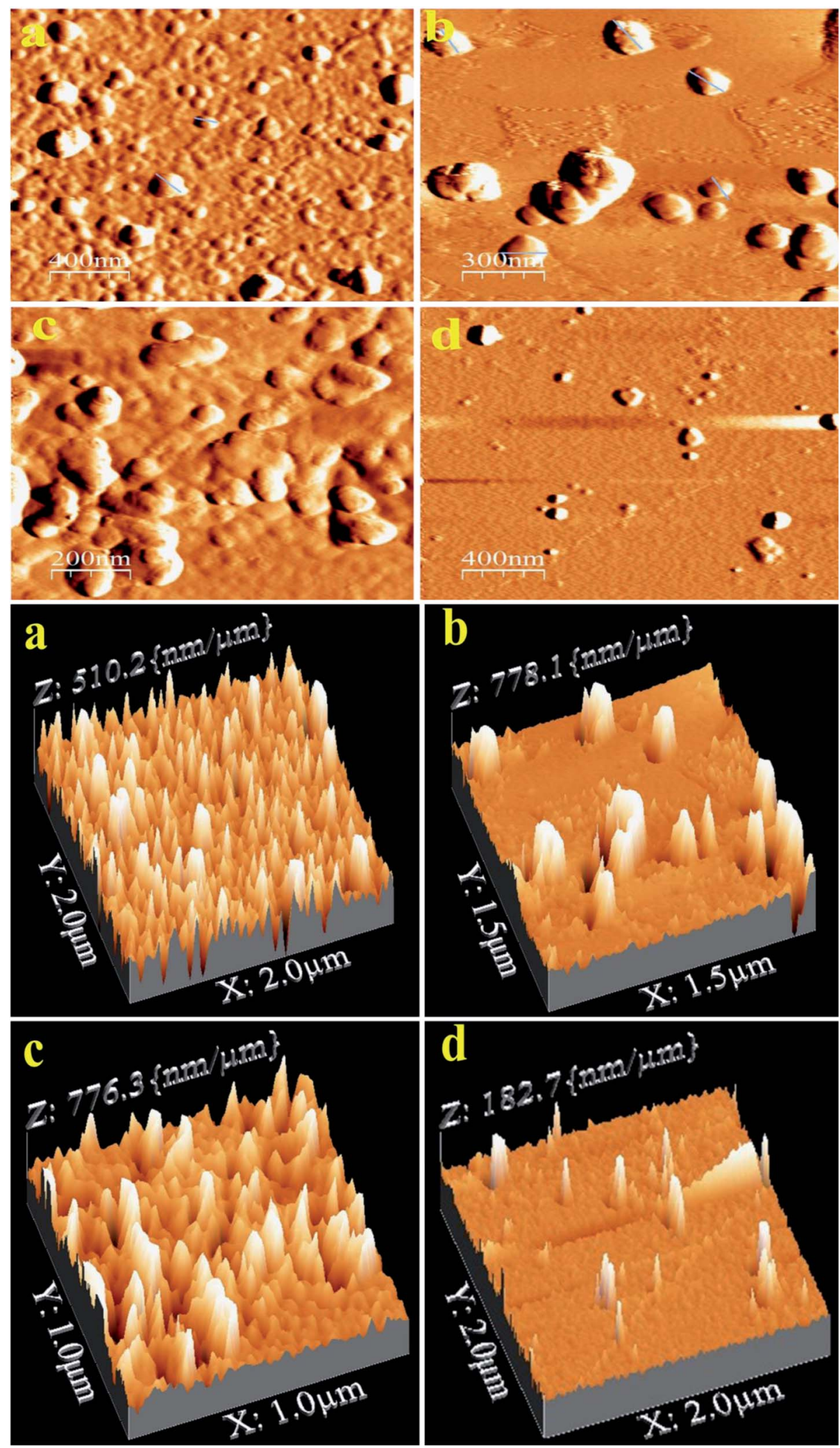

Fig. 3 AFM 2-D and 3-D images of (a) PTH, (b) PTHA1, (c) PTHA2 and (d) PTHA5 nanocomposites.

Fig. 6(b) shows the CV curve of a charcoal electrode, carried out using three electrodes configuration in $1 \mathrm{M} \mathrm{KCl}$ aqueous electrolyte in the operating voltage window of 0 to $1.1 \mathrm{~V}$. All cyclic voltammetry curves show rectangular shape, which denotes the typical EDLC characteristics. The CV curves for different scan rates from 10 to $100 \mathrm{mV} \mathrm{s}^{-1}$ shows approximately symmetric curves indicating highly reversible stability of charcoal electrode. The high scan rate curves are equivalent to low 

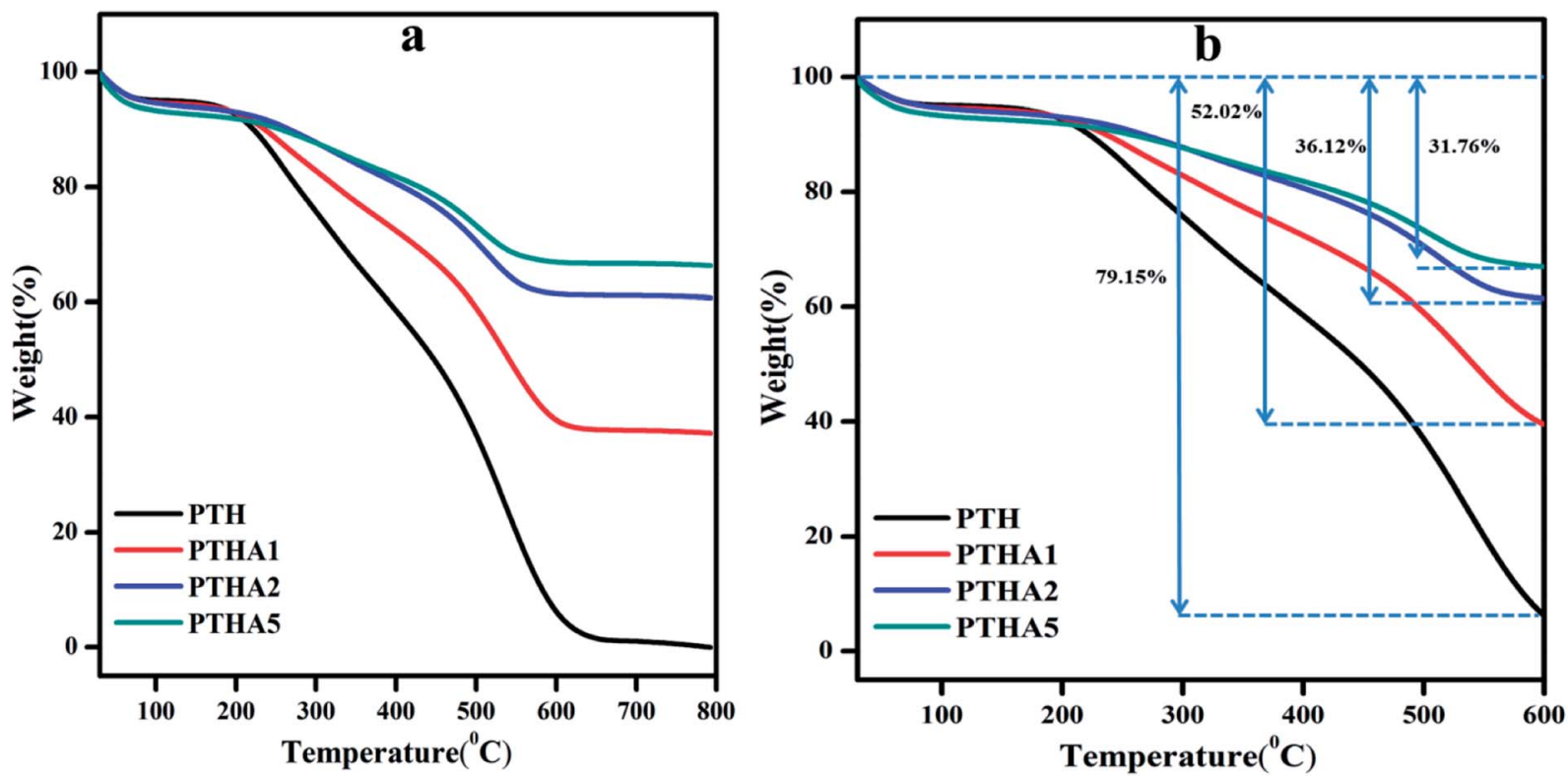

Fig. 4 TGA thermogram of PTH and PTHA nanocomposite.

scan rate curves with little distortion, which signifies the high rate of charge/discharge capability and effective ionic and electronic transfer inside the electrode material. ${ }^{40}$

The $C_{\mathrm{sp}}$ from the $\mathrm{CV}$ curve is calculated using following equation;

$$
C_{\mathrm{sp}}=\frac{\int_{V_{1}}^{V_{2}} i(V) \mathrm{d} V}{\Delta V \vartheta m}
$$

where $\int i(V) \mathrm{d} V$ represents the area under the CV curves, $\vartheta(\mathrm{V}$ $\left.\mathrm{s}^{-1}\right)$ represents the scan rate; $m(\mathrm{~g})$ gives the mass of electrode material and $\Delta V(\mathrm{~V})$ is voltage window. The PTHA5 electrode shows highest $C_{\mathrm{sp}}$ of $582.23 \mathrm{~F} \mathrm{~g}^{-1}$ whereas charcoal electrode shows $C_{\mathrm{sp}}$ of $491 \mathrm{~F} \mathrm{~g}^{-1}$ at scan rate $10 \mathrm{mV} \mathrm{s}^{-1}$. The calculated $C_{\mathrm{sp}}$ values for various scan rates are shown in Fig. 6(e) and tabulated in Table S2. $\dagger$ From the plot, it is clear that for an increase in the scan rate, there is a decrease in the $C_{\mathrm{sp}}$ which is due to the comparatively inadequate faradaic redox reaction at higher scan rate. ${ }^{41}$ It is evident that PTH provides significant pseudocapacitance to the total capacitance of the PTHA5 nanocomposites. Therefore, the combination of present electrode material could be helpful in the development of ASC devices.
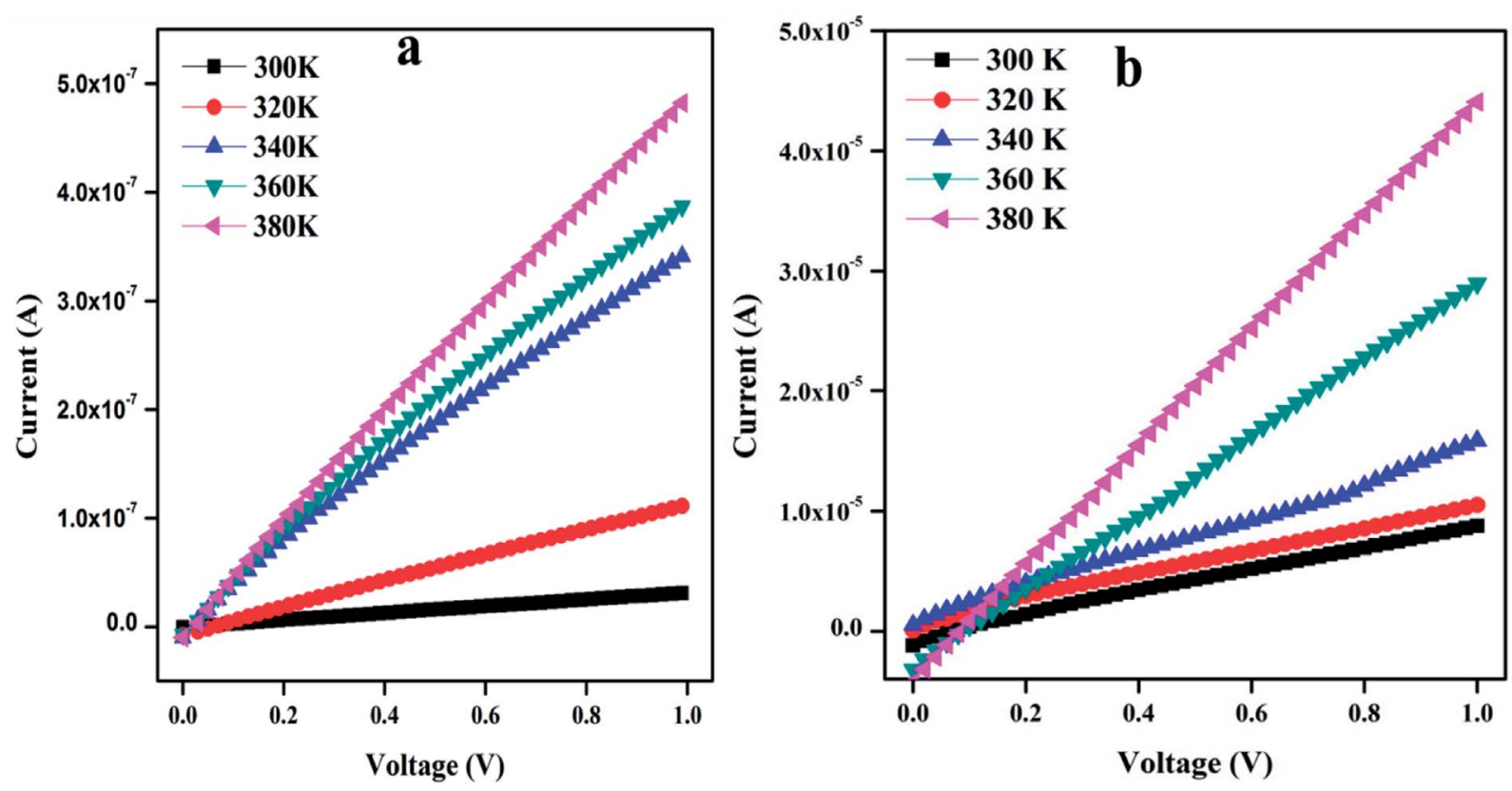

Fig. $5 \quad I-V$ characteristics of (a) PTH and (b) PTHA5 nanocomposite. 

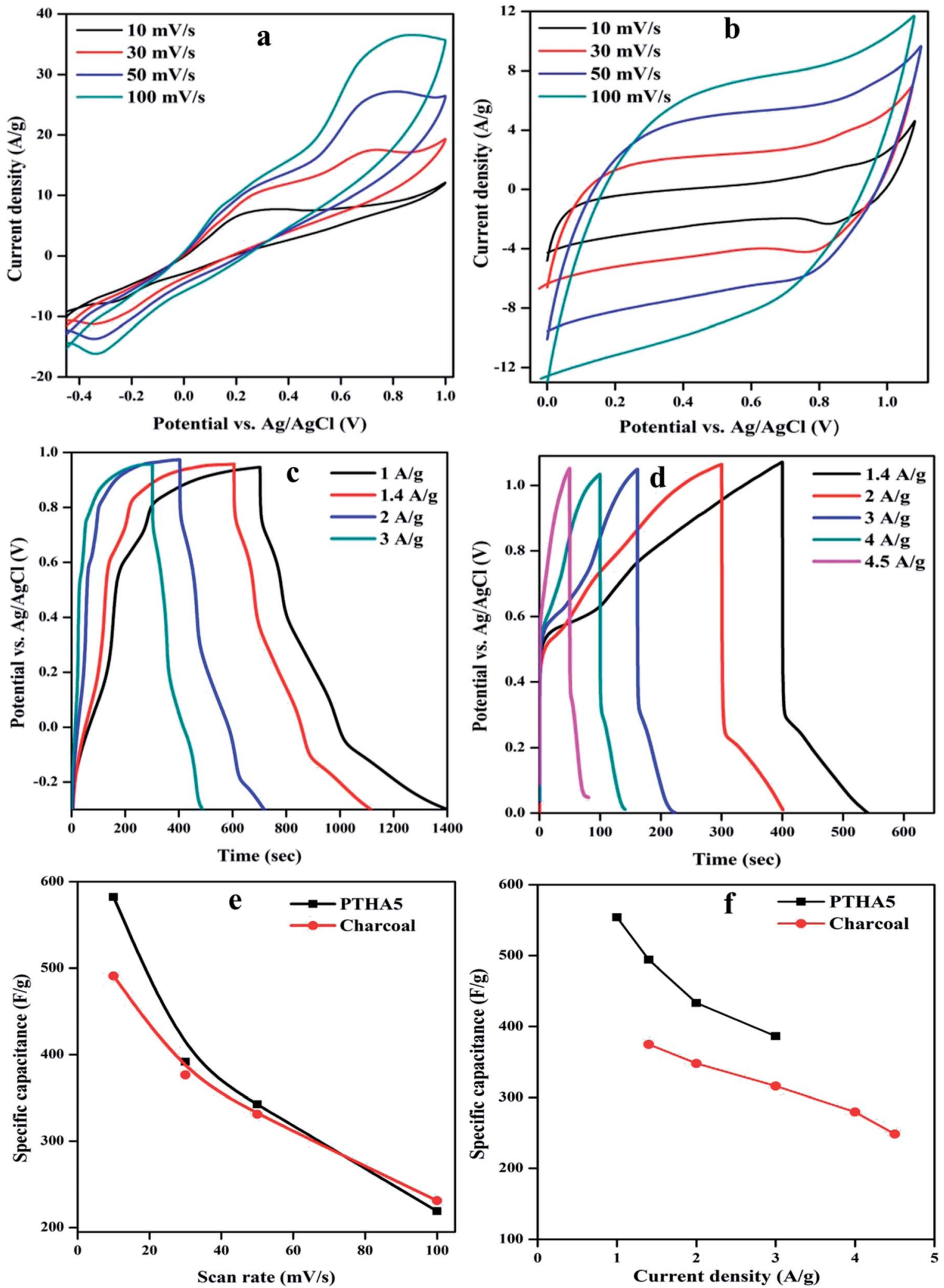

Fig. 6 (a) and (b) Cyclic voltammetry curves of PTHA5 and charcoal electrode at various scan rates from 10 to 100 mV s$~^{-1}$, (c) and (d) GCD curves of PTHA5 and charcoal at various current densities (CDs), (e) variation of $C_{\mathrm{sp}}$ for different scan rates of PTHA5 and charcoal, (f) variation of $C_{\mathrm{sp}}$ for different CDs. 
In addition to the investigation of electrochemical performance of the prepared electrode, the GCD measurement has also been carried out. Fig. 6(c) represents the GCD curve for the PTHA5 electrode at different CDs in three-electrode configuration. The GCD curves show deviance from the ideal triangular shape, which represents the substantial influence of pseudocapacitance. It can be clearly observed that at lower CDs, the electrolyte ions get more time to penetrate into the interior plane of the electrode material. Hence, both the inner and outer surfaces contribute to enhance the electrochemical performance at lower CDs, which increases the specific capacitance of the material. In case of higher CDs, the interaction of electrolyte ions occurs only with external surfaces of the electrode material because of limited time access of electrolyte ions. As a result, decrease in the $C_{\mathrm{sp}}$ can be observed. ${ }^{42}$ A longer discharge time is witnessed for the PTHA5 composite electrode which tells us about enhanced charge storage properties in the PTHA5 electrode.

Fig. 6(d) shows the GCD curve of the charcoal electrode for different CDs. The curves show quasi-triangular shapes which are nonlinear and not highly symmetric at different CDs. It confirms faradic transformation and the presence of both EDLC and pseudocapacitive behavior.

The $C_{\mathrm{Sp}}$ from the GCD curve is calculated using the following relation.

$$
C_{\mathrm{s}}=\frac{I \Delta t}{m \Delta V}
$$

where $I(\mathrm{~A})$ is charging-discharging current, $m(\mathrm{~g})$ represents the mass of active electrode material; $\Delta t(\mathrm{~s})$ is discharge time and $\Delta V$ is a potential window during the discharge process.

The maximum specific capacitance calculated using discharge curve for PTHA5 electrode is found to be $554.03 \mathrm{~F}$ $\mathrm{g}^{-1}$ at $\mathrm{CD}$ of $1.0 \mathrm{~A} \mathrm{~g}^{-1}$, whereas charcoal electrode shows $374.71 \mathrm{~F} \mathrm{~g}^{-1}$ at CD of $1.4 \mathrm{~A} \mathrm{~g}^{-1}$. Fig. 6(f) indicates the change in the specific capacitance based on the discharge curve for different CDs; values are tabulated in Table S3. $\dagger$ It shows that $C_{\text {sp }}$ of electrode material increases with decrease in the CD because of partial diffusion of electrolyte ions which restrict the transport of ions to the surface of the electrode under high CD. As a result, there is less utilization rate of electrode materials and charge-discharge time increased with a decrease in CD. More importantly, it is noticed that there is decrease in the specific capacitance from 554.03 to $386.45 \mathrm{~F}$ $\mathrm{g}^{-1}$ with increase in CD from 1 to $3 \mathrm{~A} \mathrm{~g}^{-1}$ for PTHA5 electrode and also charcoal electrode shows a decrease in specific capacitance from 374.71 to $248.45 \mathrm{~F} \mathrm{~g}^{-1}$ with increase in CDs from 1.4 to $4.5 \mathrm{~A} \mathrm{~g}^{-1}$. The PTHA5 electrode can retain about $69.75 \%$ specific capacitance when the CDs is increased from 1 to $3 \mathrm{~A} \mathrm{~g}^{-1}$, indicating an excellent rate capability whereas charcoal electrode retains $66.30 \%$ when the CD is increased from 1.4 to $4.5 \mathrm{Ag}^{-1}$. The high rate performance of PTHA5 and charcoal electrode is ascribed to the high specific area distribution. These results are well matched with the cyclic voltammetry measurements.

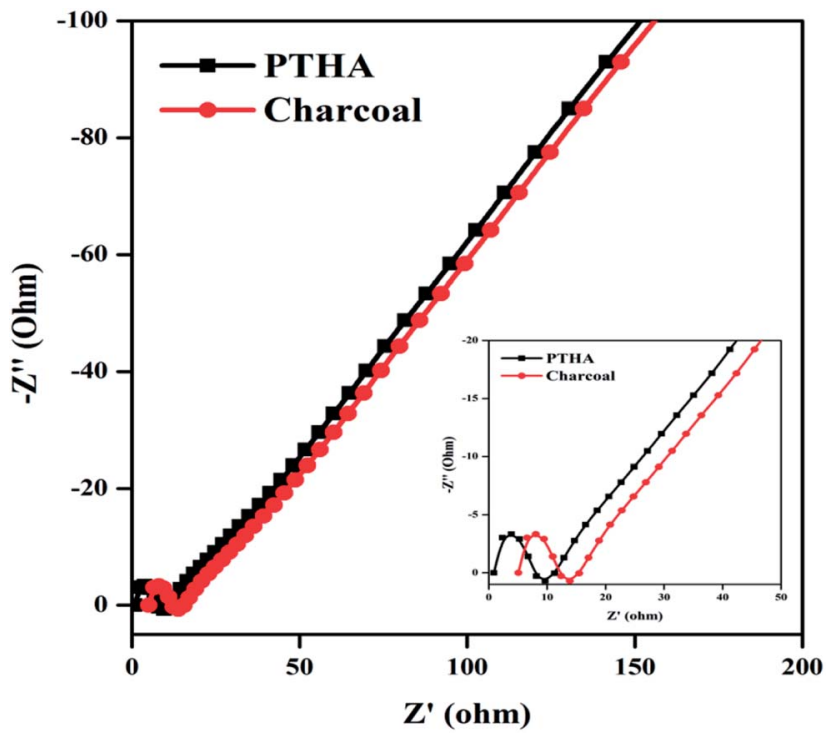

Fig. 7 Nyquist plots from EIS curve for PTHA5 and charcoal.

\subsection{Electrochemical impedance spectroscopy}

To understand the electrolyte ion transport and capacitance behavior of the PTHA5 and charcoal electrode, the Nyquist plots are plotted using EIS measurements.

Fig. 7 shows the impedance Nyquist plot of PTHA and charcoal electrode from $0.01 \mathrm{~Hz}$ to $100 \mathrm{kHz}$ frequency range using $1 \mathrm{M} \mathrm{KCl}$ electrolyte. High-frequency region of both PTHA and charcoal electrode consists of a semi-circle and the lower frequency region consists a straight line. The charge transfer resistance $\left(R_{\mathrm{ct}}\right)$ of electrode and electrolyte interface can be obtained by the diameter of the semicircle at high frequency region, whereas bulk solution resistance $\left(R_{\mathrm{S}}\right)$ of the electrode is given by the intercept at the real axis and $R_{\mathrm{s}}$, which includes intrinsic resistance occurred from electroactive material, resistance from electrolyte ions and resistance due to contact between electrolyte and electrode interface. From the Nyquist plot, PTHA and charcoal electrodes are found to have $R_{\mathrm{s}}$ values of 0.98 and $4.52 \Omega$ and $R_{\mathrm{ct}}$ values of 4.77 and $6.64 \Omega$ respectively. They are significantly lower values, which predict fast charge transfer in the electrode material. The linear part of lower frequency region which is at an angle of $75^{\circ}$ specifies the Warburg diffusion region, implying the ideal capacitive behavior of the electrode. ${ }^{\mathbf{4 3}}$

\subsection{Asymmetric supercapacitor based on PTHA and charcoal}

Considering the remarkable electrochemical performance, the EDLC and pseudocapacitance properties of PTHA and charcoal electrode, an ASC device is fabricated using the PTHA as an anode and charcoal as a cathode with PVA-KOH gel as the solidstate electrolyte. Fig. 8 shows the electrochemical performance of assembled PTHA//charcoal asymmetric supercapacitor device. 

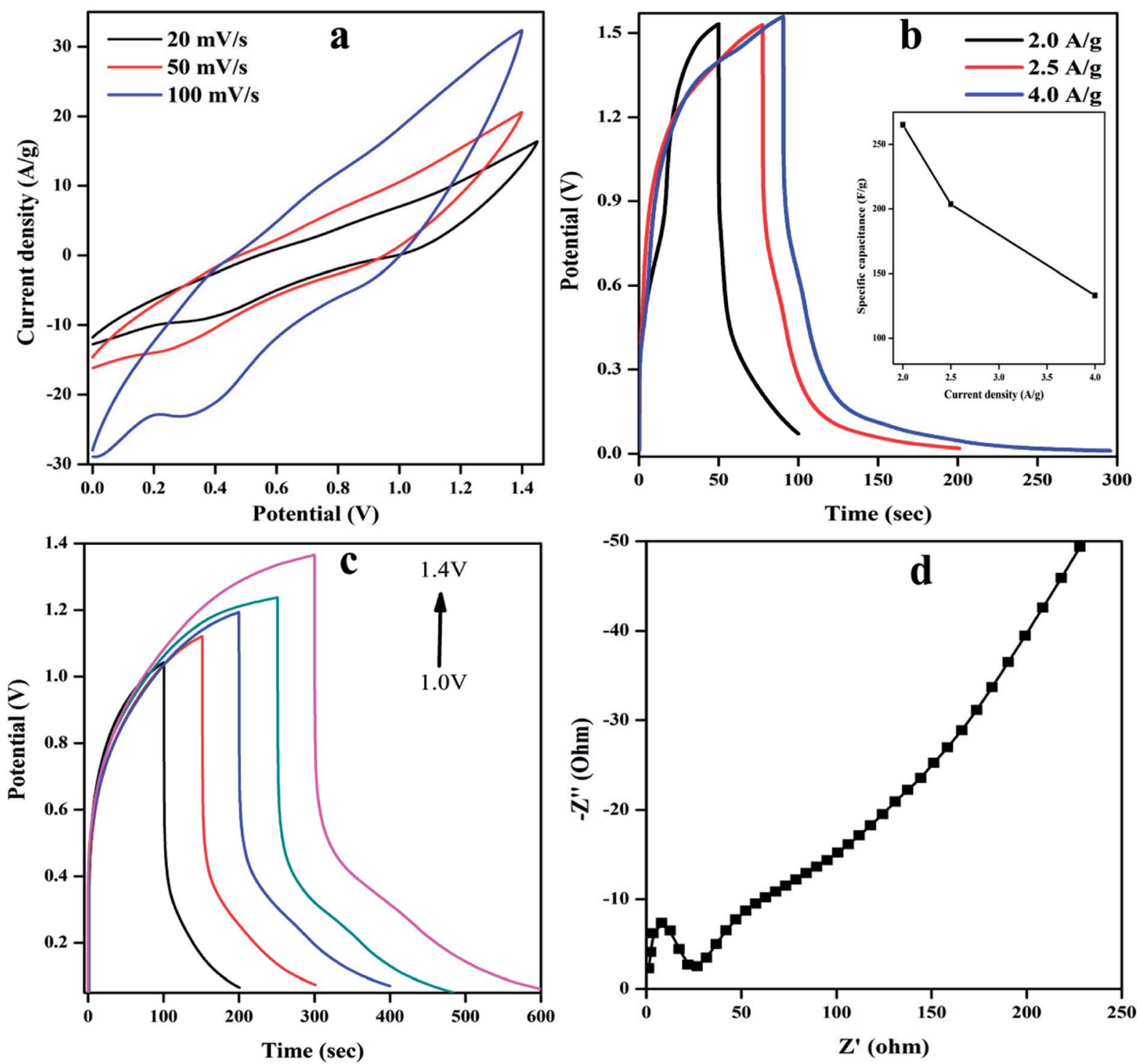

Fig. 8 (a) CV curves of PTHA//charcoal ASC device for various scan rates, (b) GCD curves of ASC device at different CDs, inset image shows plot between specific capacitance vs. CD (c) galvanostatic charging/discharging plot of ASC at different voltage windows (d) Nyquist plot from EIS for ASC device.

Fig. 8(a) shows CV curve of PTHA//charcoal ASC device for various scan rates. All the cyclic voltammetry curves retain their nearly rectangular shape with small redox peaks at different scan rates, which confirms EDLC and pseudocapacitance behavior. The slight deviation from the ideal capacitor at various scan rates is possibly due to the ion diffusion resistance transfer from the gel electrolyte to electrodes. ${ }^{44}$ The specific capacitances are found to be $548.28,302.45$ and $268.97 \mathrm{~F} \mathrm{~g}^{-1}$ at different scan rates of 20,50 and $100 \mathrm{mV} \mathrm{s}^{-1}$ respectively. At higher scan rate, there is a decrease in the specific capacitance because of the slower ion diffusion. ${ }^{45}$ The specific capacitance of the PTHA//charcoal ASC can be retained up to $49.05 \%$, exhibiting excellent capacitance retention.

Fig. 8(b) represents the GCD curves of PTHA//charcoal ASC for various CDs of 2, 2.5 and $4 \mathrm{~A} \mathrm{~g} \mathrm{~g}^{-1}$. The GCD curves show slight divergence from ideal triangular shape showing the substantial contribution from pseudocapacitance behavior and also considerably longer discharging time is attained indicating larger $C_{\mathrm{sp}}$ of PTHA//charcoal ASC device. The $C_{\mathrm{sp}}$ of PTHA// charcoal ASC is found to be 265.14, 203.56 and $133.06 \mathrm{~F} \mathrm{~g}^{-1}$ at a different CDs of 2, 2.5 and $4 \mathrm{~A} \mathrm{~g}^{-1}$ respectively. Fig. 8(b) (inset image) shows that the $C_{\mathrm{sp}}$ decreases with the increase in the $\mathrm{CD}$, which is due to slower ion diffusion, which cannot follow the ion consumption at higher $\mathrm{CD}$.

Fig. 8(c) shows the GCD curve for different potential window 1 to $1.4 \mathrm{~V}$ at a $\mathrm{CD}$ of $1.5 \mathrm{~A} \mathrm{~g}^{-1}$. The non-linear behavior of the PTHA//charcoal ASC shows the good electrochemical stability and the maximum potential window of the device. With an increase in the operating voltage window, there is an increase in discharge time, which implies that operating voltage window is directly responsible for the high capacitive response of the ASC. 

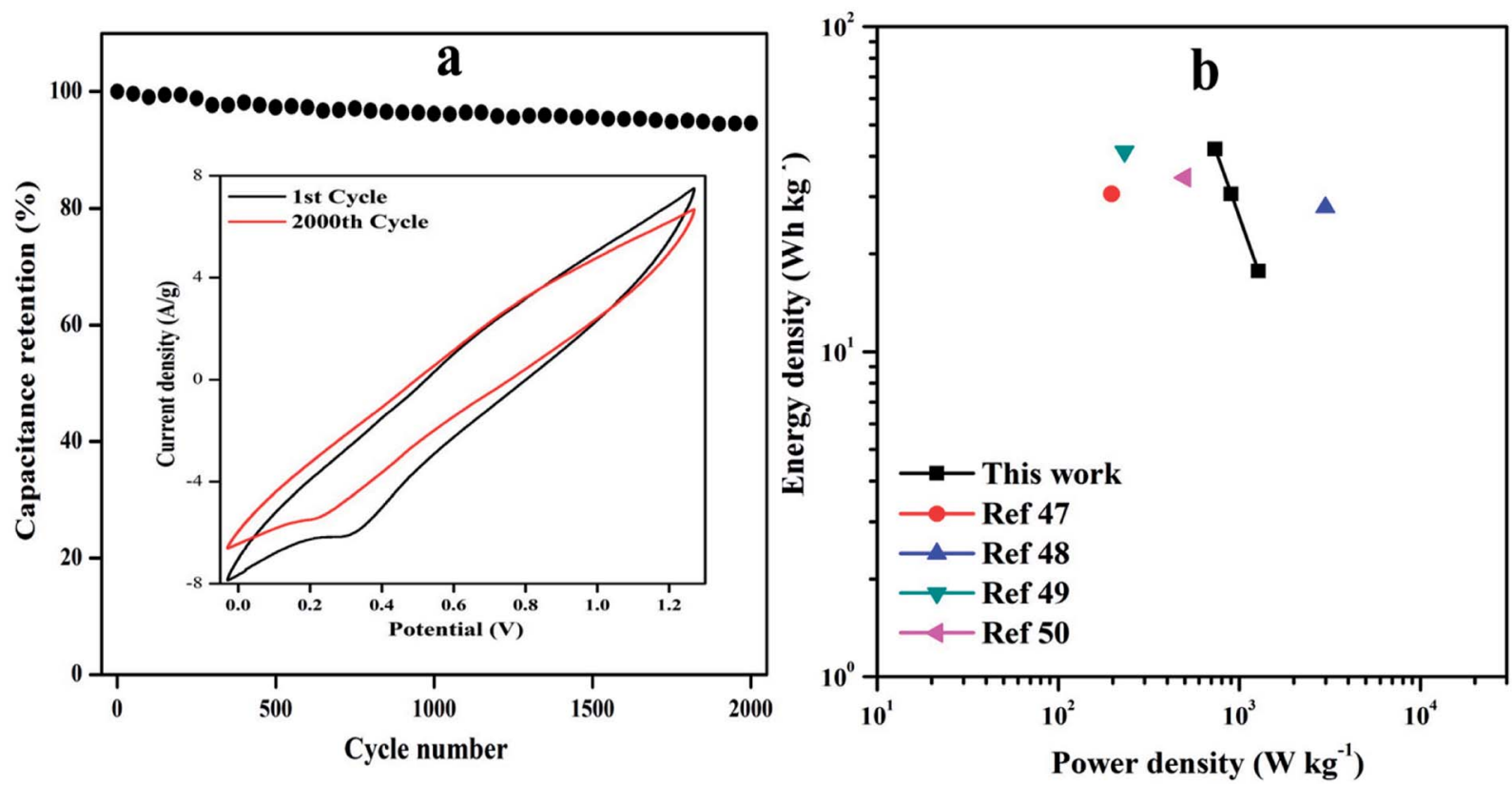

Fig. 9 (a) Cyclic performance of device at a scan rate of $10 \mathrm{mV} \mathrm{s}^{-1}$ for 2000 cycles, inset plot shows CV curve of the $1^{\text {st }}$ and $2000^{\text {th }}$ cycle, (b) Ragone plot of the ED and PD of the ASC device.

The electrochemical behavior of PTHA//charcoal ASC is further investigated using EIS studies as shown in Fig. 8(d). The EIS test was measured in the frequency range from $0.01 \mathrm{~Hz}$ to $100 \mathrm{kHz}$. Higher frequency region of the Nyquist plot consists of semicircle arc and in lower frequency region a straight line is observed.

The charge transfer resistance $\left(R_{\mathrm{ct}}\right)$ can be measured by considering the diameter of semicircle arc which is caused due to faradic reaction between the electrode and a gel electrolyte. The $X$-intercept of Nyquist plot gives the equivalent series resistance (ESR) which is found to be $2.13 \Omega$ and $R_{\mathrm{ct}}$ is $18.03 \Omega$ in the lower part of the frequency region. The plot shows a straight line with an angle of more than $45^{\circ}$ showing a deviance from ideal capacitive nature, and also the presence of a small diffusion resistance of ions inside the electrode material. ${ }^{46}$

The cycle life of ASC was evaluated at $20 \mathrm{mV} \mathrm{s}^{-1}$ as shown in Fig. 9(a). It can be clearly noticed that ASC shows excellent cycle life with $94.61 \%$ of the initial $C_{\text {sp }}$ even after 2000 cycles, the $1^{\text {st }}$ and $2000^{\text {th }}$ cycle are shown in inset Fig. 9(a) signifying the prominent energy storage capability of solid-state ASC.

The energy density (ED) $\left(\mathrm{W} \mathrm{h} \mathrm{kg}^{-1}\right)$ and power density (PD) (W kg) are estimated from GCD curves for various CD using below equations.

$$
\begin{gathered}
E=\frac{C_{\mathrm{s}} \Delta V^{2}}{7.2} \\
P=\frac{3600 E}{t}
\end{gathered}
$$

where $C_{\mathrm{s}}\left(\mathrm{F} \mathrm{g}^{-1}\right)$ represents the calculated specific capacitances from the charging/discharging curve, $\Delta V$ is the change in the voltage during discharge process and $t$ represents the discharge time. The calculated ED and PD are shown in Fig. 9(b).

The ASC device exhibits maximum ED of $42.0 \mathrm{~W} \mathrm{~h} \mathrm{~kg}^{-1}$ with PD of $735.86 \mathrm{~W} \mathrm{~kg}^{-1}$ and highest PD of $1276.9 \mathrm{~W} \mathrm{~kg}^{-1}$ at ED of $17.70 \mathrm{~W} \mathrm{~h} \mathrm{~kg}^{-1}$ is achieved with operating voltage window of $1.5 \mathrm{~V}$. These results are much higher than that of other reported conducting polymer nanocomposites based symmetric supercapacitor (SSCs) or ASCs, such as PANI G@MnO2 ASC $\left(\begin{array}{llllllll}30.6 & \mathrm{~W} & \mathrm{~h} & \mathrm{~kg}^{-1} & 197 & \mathrm{~W} & \mathrm{~kg}^{-1}\end{array}\right),{ }^{47} \quad \mathrm{VS}_{2} / / \mathrm{C}-\mathrm{Fe} / \mathrm{PANI} \quad$ ASC $\left(27.8 \mathrm{~W} \mathrm{~h} \mathrm{~kg}^{-1}, 2991.5 \mathrm{~W} \mathrm{~kg}^{-1}\right){ }^{48} \mathrm{C}-\mathrm{Fe}-P A N I$ SSC $\left(41.3 \mathrm{~W} \mathrm{~h} \mathrm{~kg}^{-1}\right.$, $\left.231.9 \mathrm{~W} \mathrm{~kg}^{-1}\right)^{49}$ and NMP2 SSC $\left(34.4 \mathrm{~W} \mathrm{~h} \mathrm{~kg}^{-1}, 500 \mathrm{~W} \mathrm{~kg}^{-1}\right),{ }^{50}$ which are tabulated in Table S4. $\dagger$

A series of mechanical flexibility test was performed in order to validate the potential application of the fabricated PTHA// charcoal ASC device in portable and wearable electronic devices. The different bending positions like normal, bending I, bending II and twisting is shown in Fig. 10(a), (b), (c) and (d) respectively. No significant difference was found among these CV curves. Almost overlapped CV curves were achieved with various bending positions (at a scan rate of $10 \mathrm{mV} \mathrm{s}^{-1}$ ), which emphasizes the outstanding flexibility and stability of PTHA// charcoal ASC device. Fig. 10(e) shows the ASC device can retain up to $97.92 \%$ of its original capacitance under different bending positions, even twisted condition PTHA//charcoal ASC shows stable electrochemical performance and flexibility which indicates that constructed solid state ASC device is extremely flexible and can be bended and folded without damaging the structural integrity of the device.

As device exhibit maximum operating potential up to $1.5 \mathrm{~V}$ and high energy density, the charged PTHA//charcoal ASC can be effectively used to glow the red LED for more than 10 minutes when three such devices are connected in series. It gives $4.83 \mathrm{~V}$ which indicates good energy storage ability as 

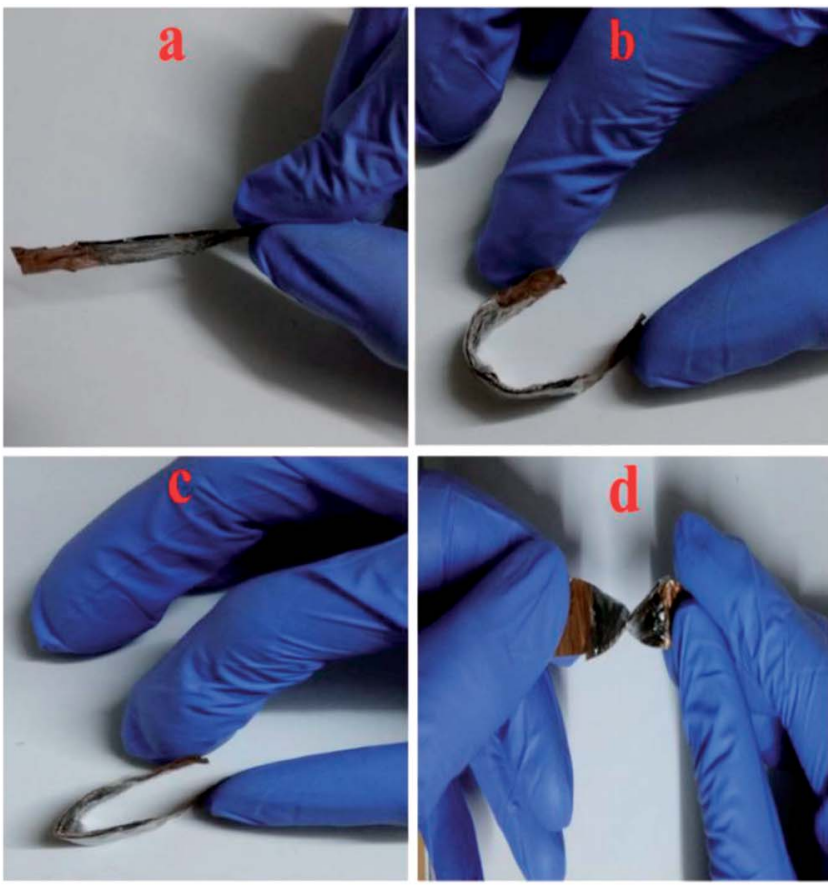

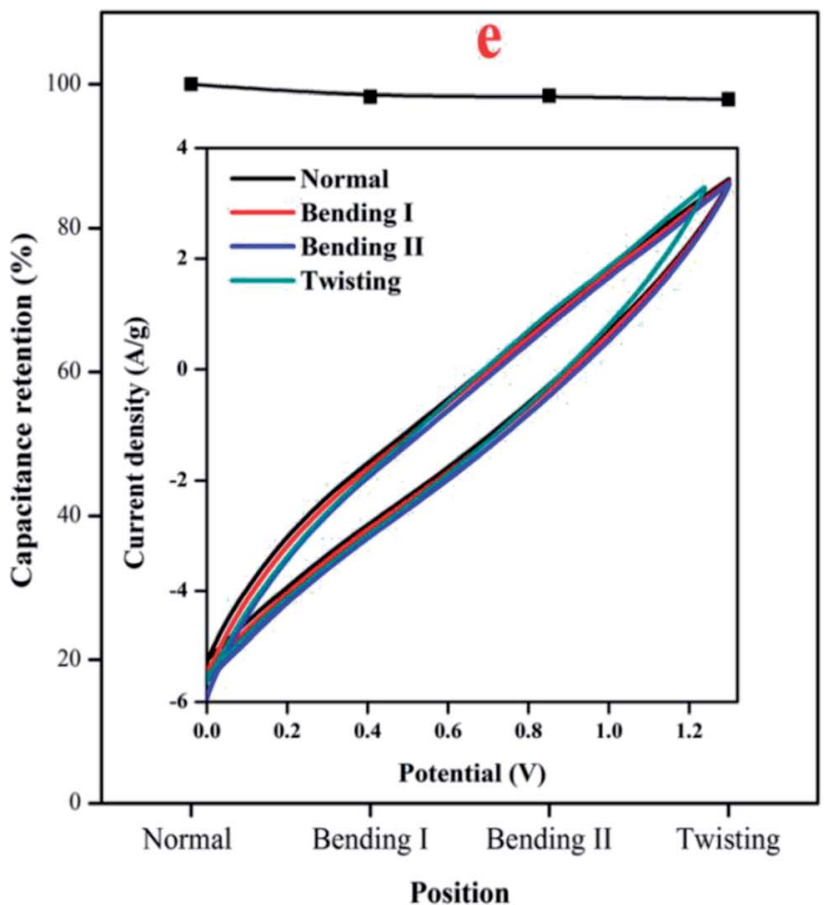

Fig. 10 Digital photos of solid state asymmetric supercapacitor at different bending position (a) normal, (b) bending I, (c) bending II and (d) twisting. (e) CV curves of different bending positions.
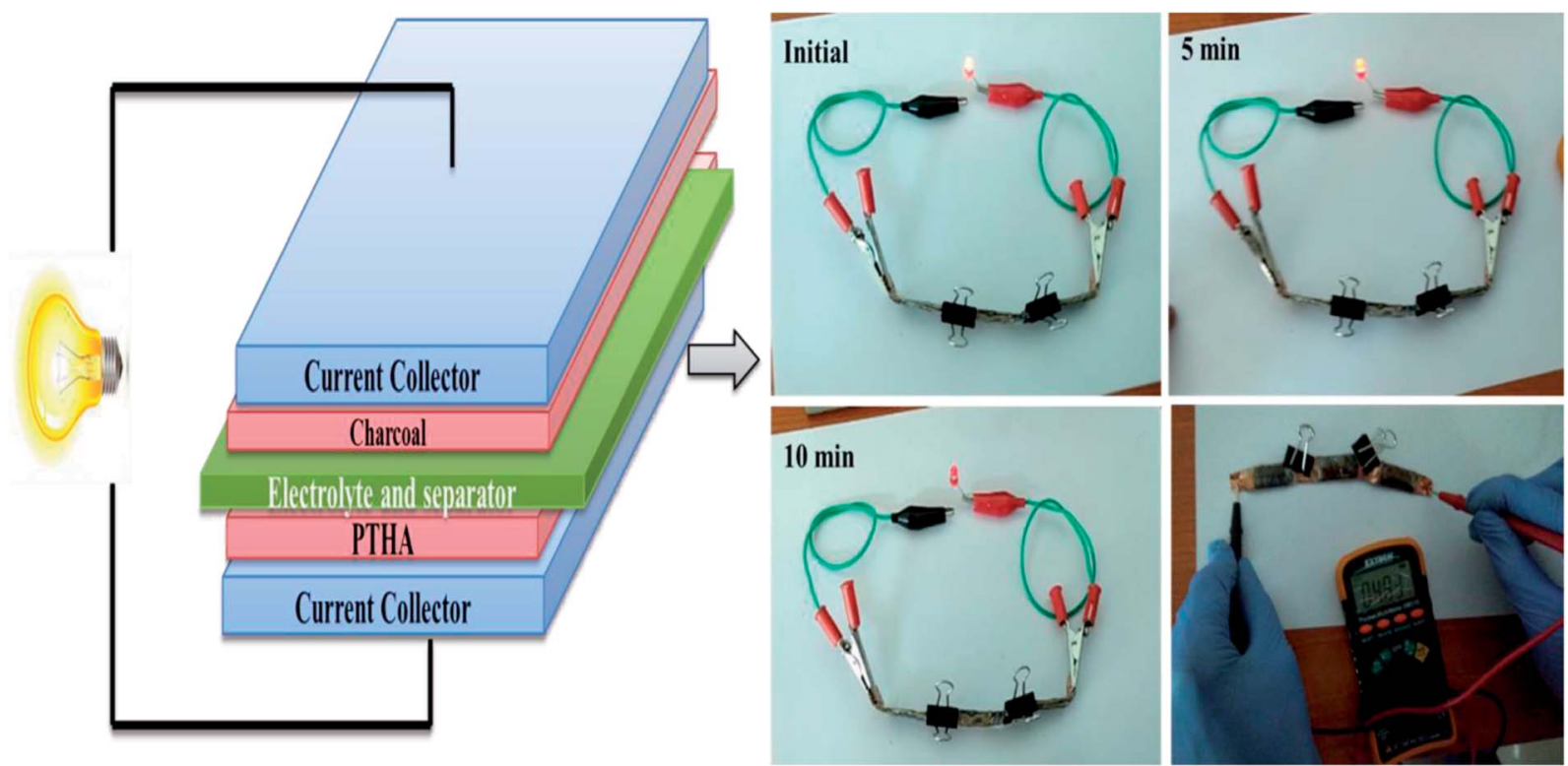

Fig. 11 Schematic representation of the fabricated solid-state ASC with charcoal as cathode and PTHA as anode using PVA/KOH gel electrolyte; the fabricated ASC device can glow a red LED (working voltage: $1.5 \mathrm{~V}$ ) for more than 10 min showing voltage up to $4.83 \mathrm{~V}$.

shown in Fig. 11. Considering the excellent electrochemical performance, the fabricated PTHA//charcoal ASC serves as flexible, efficient and high-performance wearable energy storage device.

\section{Conclusions}

In summary, the PTHA//charcoal based asymmetric supercapacitor was fabricated using PTHA nanocomposites as an anode electrode and charcoal as a cathode electrode. The 
highest $C_{\mathrm{sp}}$ of the PTHA electrode was found to be $554.03 \mathrm{~F} \mathrm{~g}^{-1}$ at charge density of $1 \mathrm{~A} \mathrm{~g}^{-1}$ and that of the charcoal electrode was $374.71 \mathrm{~F} \mathrm{~g}^{-1}$ at $1.4 \mathrm{~A} \mathrm{~g}^{-1}$. The assembled PTHA//charcoal ASC showed maximum $C_{\mathrm{sp}}$ of $265.14 \mathrm{~F} \mathrm{~g}^{-1}$ at $2 \mathrm{~A} \mathrm{~g}^{-1}$ and also maximum energy density of $42.0 \mathrm{~W} \mathrm{~h} \mathrm{~kg}{ }^{-1}$ with the power density of $735.86 \mathrm{~W} \mathrm{~kg}{ }^{-1}$. Moreover, ASC device exhibits capacitance retention of $94.61 \%$ even after 2000 cycles. In addition, the fabricated ASC device showed good mechanical stability with different bending positions. Therefore, the ASC device serves as flexible and high efficient wearable and portable energy storage device.

\section{Conflicts of interest}

The authors declare no competing financial interest.

\section{Acknowledgements}

The author would like to thank Mangalore University for providing research fellowship. Authors gratefully acknowledge INUP program funded by Govt. of India, CENSE, IISC Bangalore, India, and DST-PURSE facility, Mangalore University for providing characterization facilities.

\section{References}

1 L. Huang, X. Yao, L. Yuan, B. Yao, X. Gao, J. Wan, P. Zhou, M. Xu, J. Wu, H. Yu and Z. Hu, Energy Storage Materials, 2018, 12, 191-196.

2 W. Liu, M. S. Song, B. Kong and Y. Cui, Adv. Mater., 2017, 29, 1603436.

3 L. Dong, C. Xu, Y. Li, Z. H. Huang, F. Kang, Q. H. Yang and X. Zhao, J. Mater. Chem. A, 2016, 4, 4659-4685.

4 X. Cai, C. Zhang, S. Zhang, Y. Fang and D. Zou, J. Mater. Chem. A, 2017, 5, 2444-2459.

5 Y. Wang, Y. Song and Y. Xia, Chem. Soc. Rev., 2016, 45, 59255950.

6 L. Huang, B. Yao, J. Sun, X. Gao, J. Wu, J. Wan, T. Li, Z. Hu and J. Zhou, J. Mater. Chem. A, 2017, 5, 2897-2903.

7 P. Simon and Y. Gogotsi, Nat. Mater., 2008, 7, 845.

8 G. Wang, L. Zhang and J. Zhang, Chem. Soc. Rev., 2012, 41, 797-828.

9 S. Bose, T. Kuila, A. K. Mishra, R. Rajasekar and N. H. Kim, J. Mater. Chem., 2012, 22, 767-784.

10 L. L. Zhang and X. S. Zhao, Chem. Soc. Rev., 2009, 38, 25202531.

11 C. Liu, Z. Yu, D. Neff, A. Zhamu and B. Z. Jang, Nano Lett., 2010, 10, 4863-4868.

12 R. Hu, J. Zhao, G. Zhu and J. Zheng, Electrochim. Acta, 2018, 261, 151-159.

13 R. Yuksel, E. Alpugan and H. E. Unalan, Org. Electron., 2018, 52, 272-280.

14 C. Fu, H. Zhou, R. Liu, Z. Huang, J. Chen and Y. Kuang, Mater. Chem. Phys., 2012, 132, 596-600.

15 V. Subramanian, S. C. Hall, P. H. Smith and B. Rambabu, Solid State Ionics, 2004, 175, 511-515.
16 M. W. Xu, W. Jia, S. J. Bao, Z. Su and B. Dong, Electrochim. Acta, 2010, 54, 5117-5122.

17 W. Yang, Z. Gao, J. Ma, X. Zhang, J. Wang and J. Liu, J. Mater. Chem. A, 2014, 2, 1448-1457.

18 K. Deori, S. K. Ujjain, R. K. Sharma and S. Deka, ACS Appl. Mater. Interfaces, 2013, 5, 10665-10672.

19 J. Wang, Z. Gao, Z. Li, B. Wang, Y. Yan, Q. Liu and Z. Jiang, J. Solid State Chem., 2011, 184, 1421-1427.

20 J. Arjomandi, J. Y. Lee, R. Movafagh, H. O. B. Moghanni and M. H. Parvin, J. Electroanal. Chem., 2018, 810, 100-108.

21 A. Laforgue, P. Simon, C. Sarrazin and J. F. Fauvarque, J. Power Sources, 1999, 80, 142-148.

22 C. Fu, H. Zhou, R. Liu, Z. Huang, J. Chen and Y. Kuang, Mater. Chem. Phys., 2012, 132, 596-600.

23 K. Liu, Z. Hu, R. Xue, J. Zhang and J. Zhu, J. Power Sources, 2008, 179, 858-862.

24 L. Wang, Y. Ouyang, X. Jiao, X. Xia, W. Lei and Q. Hao, Chem. Eng. J., 2018, 334, 1-9.

25 J. Arjomandi, J. Y. Lee, F. Ahmadi, M. H. Parvin and H. O. B. Moghanni, Electrochim. Acta, 2017, 251, 212-222.

26 Z. Fan, J. Yan, T. Wei, L. Zhi, G. Ning, T. Li and F. Wei, Adv. Funct. Mater., 2011, 21, 2366-2375.

27 P. Simon and Y. Gogotsi, Acc. Chem. Res., 2012, 46, 10941103.

28 B. G. Choi, M. Yang, W. H. Hong, J. W. Choi and Y. S. Huh, ACS Nano, 2012, 6, 4020-4028.

29 L. Q. Fan, G. J. Liu, J. H. Wu, L. Liu, J. M. Lin and Y. L. Wei, Electrochim. Acta, 2014, 137, 26-33.

30 Z. Fan, J. Yan, T. Wei, L. Zhi, G. Ning, T. Li and F. Wei, Adv. Funct. Mater., 2011, 21, 2366-2375.

31 J. H. Park and O. O. Park, J. Power Sources, 2002, 111, 185190.

32 T. Y. Wei, C. H. Chen, K. H. Chang, S. Y. Lu and C. C. Hu, Chem. Mater., 2009, 21, 3228-3233.

33 N. Choudhary, C. Li, J. Moore, N. Nagaiah, L. Zhai, Y. Jung and J. Thomas, Adv. Mater., 2017, 29, 1605336.

34 Q. Wang, X. Wang, B. Liu, G. Yu, X. Hou, D. Chen and G. Shen, J. Mater. Chem. A, 2013, 1, 2468-2473.

35 W. Feng, A. S. Wan and E. Garfunkel, J. Mater. Chem. C, 2013, 117, 9852-9863.

36 J. Chen, N. Wang, H. Ma, J. Zhu, J. Feng and W. Yan, J. Chem. Eng. Data, 2017, 62, 2208-2221.

37 D. Guan, J. A. Jeevarajan and Y. Wang, Nanoscale, 2011, 3, 1465-1469.

38 H. Shi, C. Liu, J. Xu, H. Song, B. Lu, F. Jiang and Q. Jiang, ACS Appl. Mater. Interfaces, 2013, 5, 12811-12819.

39 M. Sharif and B. Pourabas, RSC Adv., 2016, 6, 93680-93693.

40 X. He, W. Yang, X. Mao, L. Xu, Y. Zhou, Y. Chen and J. Xu, J. Power Sources, 2018, 376, 138-146.

41 X. Wang, B. Liu, R. Liu, Q. Wang, X. Hou, D. Chen and G. Shen, Angew. Chem., 2014, 126, 1880-1884.

42 C. C. Hu, E. Chen and J. Y. Lin, Electrochim. Acta, 2002, 47, 2741-2749.

43 D. S. Dhawale, A. Vinu and C. D. Lokhande, Electrochim. Acta, 2011, 56, 9482-9487.

44 Y. Xiao, S. Liu, F. Li, A. Zhang, J. Zhao, S. Fang and D. Jia, Adv. Funct. Mater., 2012, 22, 4052-4059. 
45 Y. Li, X. Zhao, Q. Xu, Q. Zhang and D. Chen, Langmuir, 2011, 27, 6458-6463.

46 W. Yang, Z. Gao, J. Ma, J. Wang, X. Zhang and L. Liu, Dalton Trans., 2013, 44, 15706-15715.

47 M. A. Bavio, G. G. Acosta, T. Kessler and A. Visintin, Energy, 2017, 130, 22-28.
48 M. N. Rantho, M. J. Madito, F. O. Ochai-Ejeh and N. Manyala, Electrochim. Acta, 2018, 260, 11-23.

49 M. N. Rantho, M. J. Madito and N. Manyala, Electrochim. Acta, 2018, 260, 11-23.

50 H. Wang, Y. Song, J. Zhou, X. Xu, W. Hong, J. Yan and J. Gao, Electrochim. Acta, 2016, 212, 775-783. 